\title{
Analisis Kerusakan Mangrove Di Pusat Restorasi Dan Pembelajaran Mangrove (PRPM), Kota Pekalongan
}

\author{
Raden Ario*, Petrus Subardjo, dan Gentur Handoyo \\ Jurusan IImu Kelautan, Fakultas Perikanan dan Ilmu Kelautan, Universitas Diponegoro \\ JI. Prof. Soedarto, SH. Kampus UNDIP Tembalang, Semarang 50275 \\ Email: ario_1960@yahoo.com
}

\begin{abstract}
Abstrak
Mangrove merupakan vegetasi pantai yang terlindungi. Kerusakan mangrove dapat terjadi secara alami ataupun adanya tekanan masyarakat pantai sekitar. Tekanan kerusakan ulah masyarakat disekitar pantai Kota Pekalongan, Jawa Tengah berakibat adanya perubahan karakteristik fisik dan kimiawi lingkungan. Penelitian yang dilaksanakan pada bulan Agustus 2014 ini bertujuan untuk menganalisis penyebab kerusakan mangrove di pantai Kota Pekalongan. Metode Survey dilakukan di Pusat Restorasi dan Pembelajaran Mangrove (PRPM) dengan sampling data pada 4 lokasi dengan 3 kali pengulangan. Analisis data dilakukan dengan pendekatan metode Deskriptip Komparatip untuk membandingkan kondisi ekosistem mangrove. Hasil yang didapat adalah mangrove dari jenis Rhyzophora sp., Bruguiera sp., Avicennia sp., Sonneratia sp., dan Xylocarpus. Sedangkan jenis mangrove yang tumbuh dominan adalah jenis Rhyzophora, Bruguiera, dan Avicennia, serta jenis Rhyzophora yang paling dominan. Jenis Rhyzophora merupakan vegetasi perintis dengan tingkat kerapatan relatip tinggi dan dapat tumbuh pada tanah berlumpur.
\end{abstract}

Kata kunci : Analisis, Kerusakan, Mangrove.

\section{PENDAHULUAN}

Hutan mangrove merupakan suatu tipe hutan yang tumbuh di daerah pasang surut terutama pantai terlindung, laguna dan muara sungai yang tergenang pada saat surut yang komunitas tumbuhannya bertoleransi terhadap garam. Luas hutan mangrove di Indonesia pada Tahun 1999 mencapai 8,60 juta $\mathrm{Ha}$ dan yang telah mengalami kerusakan sekitar 5,30 juta Ha. Kerusakan mangrove dapat terjadi secara alami atau melalui tekanan masyarakat sekitarnya. Secara alami umumnya kadar kerusakannya jauh lebih kecil dari pada kerusakan akibat ulah manusia. Kerusakan alami terjadi karena peristiwa alam seperti adanya angin topan atau badai dan iklim kering berkepanjangan yang menyebabkan akumulasi kadar garam dalam tanaman. Sedangkan kerusakan yang terjadi akibat tekanan masyarakat atau ulah manusia disebabkan karena banyaknya aktifitas manusia disekitar kawasan hutan mangrove yang berakibat pada perubahan karakteristik fisik dan kimiawi disekitar habitat mangrove. Sehingga tempat tersebut tidak lagi sesuai bagi kehidupan dan perkembangan flora dan fauna hutan mangrove. Selain itu kerusakan karena ulah manusia adalah pemanfaatan kayu mangrove untuk berbagai keperluan, pembuatan tambak, pemukiman, industri, dan sebagainya.

Kota Pekalongan merupakan salah satu Kota di pesisir utara Pulau Jawa yang juga mengalami perusakan ekosistem mangrove. Keadaan ini tentu sangat mengkhawatirkan dan pasti akan berdampak pada penurunan kualitas wilayah pesisir Kota Pekalongan. Oleh karena itu diperlukan upaya sesegera mungkin untuk kembali memulihkan ekosistem mangrove. Penyusunan dokumen Reklamasi Vegetasi Pesisir Kota Pekalongan merupakan salah satu upaya dalam rangka mengembalikan terwujudnya ekosistem mangrove di wilayah pesisir Kota Pekalongan. 


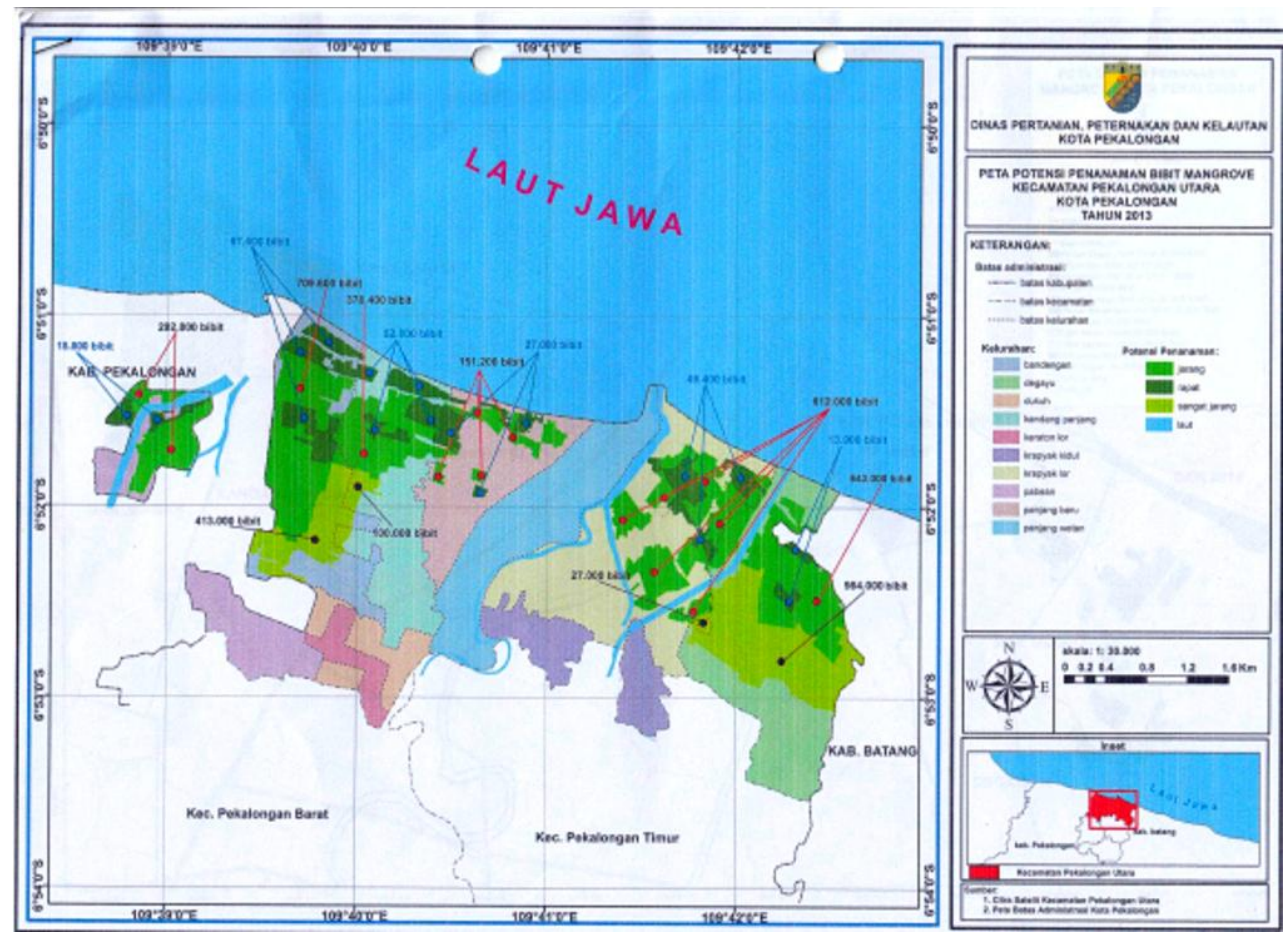

Gambar 1. Peta Potensi Penanaman Mangrove

\section{MATERI DAN METODE}

Penelitian dilakukan pada bulan Agustus 2014 dengan lokasi pengamatan di Pusat Restorasi dan Pembelajaran Mangrove (PRPM), Kota Pekalongan. Materi yang digunakan adalah mangrove sebagai tanaman yang hidup di antara laut dan daratan yang dipengaruhi oleh pasang surut. Mangrove juga bisa menjadi mata pencarian masyarakat pesisir yang memanfaatkan buah mangrove sebagai bahan pewarna batik.

Metode yang digunakan adalah metode Survey (non-eksperimental) dengan pengambilan sampel dilakukan pada 4 lokasi dengan 3 kali pengulangan di PRPM Kota Pekalongan. Kualitas lingkungan perairan yang diamati adalah: Salinitas, pH, DO, dan Suhu.

Identifikasi mangrove di lapangan dengan cara mengamati akar, batang, daun, bunga, dan buah yang terlihat pada pohon mangrove dan mencocokkannya dengan buku identifikasi. Setelah mendapatkan ciri-ciri tersebut maka cocokan dengan buku identifikasi agar mempermudah pencarian nama spesies pohon mangrove tersebut. Hasil yang telah diamati dicatat dalam buku dan identifikasi jenis mangrove dilakukan dari Noor et al. (1999).

\section{Analisis Data}

Analisis data yang digunakan adalah analisis deskriptif komparatif agar dapat membandingkan keadaan ekosistem mangrove di Pusat Restorasi dan Pembelajaran Mangrove (PRPM).

Pengertian deskriptif menurut Anwar dan Gunawan (2006) adalah suatu metode dalam meneliti status sekelompok manusia, suatu objek, suatu set kondisi, dan suatu kelas peristiwa pada masa sekarang. Tujuan dari penelitian deskriptif adalah untuk membuat deskripsi atau gambaran secara sistematis, faktual dan akurat mengenai fakta-fakta, sifat-sifat serta hubungan antar fenomena yang diselidiki. Dalam metode deskriptif dapat dibandingkan fenomena-fenomena tertentu sehingga merupakan suatu studi komparatif. Sedangkan penelitian komparatif menurut Anwar dan Gunawan (2006) adalah penelitian membandingkan keberadaan satu variabel atau lebih pada dua atau lebih sampel yang berbeda, atau pada waktu yang berbeda. 


\section{HASIL DAN PEMBAHASAN}

\section{Peta Potensi Penanaman Mangrove}

Peta potensi penanaman mangrove (Lampiran) menunjukkan bahwa lokasi PRPM (Pusat Restorasi dan Pembelajaran Mangrove) di Kota Pekalongan mempunyai potensi untuk penamanan mangrove.

Hasil wawancara dengan petugas PRPM, bahwa lokasi PRPM memiliki luasan lahan untuk ditanamani mangrove seluas $\pm 5,7$ ha. Kondisi PRPM saat didirikan pada tahun 2007 masih kosong tanpa adanya sabuk pantai yaitu mangrove, PRPM tersebut sebelum adanya mangrove di pinggir garis pantai hanya ada tanaman pandan duri, kemudian baru tahun 2012 ada pergerakan penamanan mangrove oleh beberapa instansi pemerintahan. Selanjutnya setelah satu tahun berjalan terlihat ekosistem mangrove tumbuh, kemudian pemerintahan dan kelompok tani di wilayah PRPM mulai menanam kembali mangrove dengan berbagai jenis mangrove. Pada bulan Juli 2014 saat dilakukan survey lokasi terlihat mangrove sudah mulai tumbuh dengan ketinggian pohon $30-50 \mathrm{~cm}$, tetapi setelah bulan Agustus 2014 saat dilakukan penelitian ternyata berbagai macam vegetasi mangrove yang ditanam sudah tidak ada. Vegetasi mangrove yang bertahan adalah Rhizophora sp. dan Avecennia sp.. Kondisi tersebut dimungkinkan adanya faktor sirkulasi air yang tidak baik sehingga berakibat vegetasi mangrove tersebut mati.

\section{Jenis-jenis Vegetasi Mangrove}

Hasil yang di dapatkan dari lokasi tersebut yaitu Rhizophora stylosa, Rhizophora mucronata, Bruguiera sp., Avicennia alba, Sonneratia alba, Sonneratia caseolaris, dan Xylocarpus.

Menurut Noor et al. (2006), bahwa di lokasi PRPM di temukan beberapa genus yaitu : Rhizophora, Brugueira, Avicennia, Sonneratia, Xylocarpus. Akan tetapi yang hanya bisa tumbuh di lokasi tersebut hanya beberapa spesies yaitu Rhizophora sp.,
Brugueira sp., Avicennia sp. Sedangkan Sonneration di lokasi tersebut memang ada tetapi hanya satu pohon saja dengan kondisi pohon yang kecil dan tidak bisa besar. Hasil transek mangrove di PRPM Kota Pekalongan ternyata didominasi spesies dari genus Rhizophora. Adanya perubahan dominasi pada masing-masing strata ini mengindikasikan bahwa komunitas mangrove di PRPM Kota Pekalongan, bukan merupakan ekosistem primer tetapi ekosistem sekunder yang masih dalam proses suksesi menuju ke fase klimaks.

Dijelaskan Ding Hou (1958), bahwa Rhizophora sp. merupakan jenis vegetasi yang mempunyai tingkat kerapatan relatif tertinggi yang merupakan tumbuhan perintis dan dapat tumbuh dengan substrat lumpur yang lembek. Kondisi tersebut disebabkan penyebaran Rhizophora sp dipengaruhi oleh adanya pasang surut air laut yang membantu penyebaran biji mangrove ke berbagai tempat, serta biji berakar pada ujungnya dan dapat menambatkan diri pada lumpur pada waktu air surut. Dijelaskan Tomlinson (1986), bahwa komposisi vegetasi mangrove dipengaruhi oleh kemampuan masingmasing spesies mangrove serta kemampuan beradaptasi secara fisiologis terhadap lingkungannya, yaitu salinitas, tipe tanah dan pasang surut. Juga ditegaskan bahwa R. mucronata Lam. dan R. apiculata Blume termasuk dalam famili Rhizophoraceae merupakan spesies yang dapat beradaptasi dengan baik pada kondisi tanah yang berlumpur.

Laju pertumbuhan populasi dan komposisi spesies berlangsung dengan cepat pada fase awal suksesi, kemudian menurun pada perkembangan berikutnya. Kondisi yang membatasi laju pertumbuhan populasi dan komposisi spesies pada tahap berikutnya adalah faktor lingkungan yang kurang cocok untuk mendukung kelangsungan hidup permudaan jenis-jenis tertentu.

\section{Parameter Lingkungan}

Hasil pengukuran parameter lingkungan yang di dapatkan pada lokasi PRPM (Pusat Restorasi dan Pembelajaran 
Mangrove) Kota Pekalongan mempunyai tingkat konsentrasi yang memenuhi standar baku mutu (Tabel 1).

Hasil pengukuran parameter kualitas perairan, diperoleh kisaran data $\mathrm{pH} 7,7-7,8$, DO (Oksigen terlarut) 4,10-4,50 mg/l, Indeks bias 1,019, suhu 28-31 $\circ$ C, salinitas $24,5-25$ $\%$, dan substrat lumpur berpasir. Secara umum kisaran suhu di lokasi PRPM masih tergolong alami untuk pertumbuhan ekosistem mangrove. Mangrove dapat tumbuh dengan baik pada daerah tropis dengan suhu di atas $20^{\circ} \mathrm{C}$ (Kennish dalam Aksornkoae, 1993). Begitu juga dengan salinitas dan substrat memperlihatkan bahwa perairan disekitar ekosistem mangrove masih tergolong normal dan mampu mendukung pertumbuhan mangrove di lokasi PRPM. Salah satu parameter kualitas perairan yang perlu mendapat perhatian adalah $\mathrm{pH}$. Namun secara umum kondisi lingkungan lokasi PRPM masih berada pada kisaran yang layak untuk kehidupan mangrove. Hal ini di dukung oleh pendapat Lugo and Snedaker (1974), yang menyatakan bahwa tumbuhan mangrove tumbuh subur di daerah estuaria dengan salinitas 10-30 ppt. Jika salinitas yang sangat tinggi terjadi melebihi salinitas umum ( $\pm 35 \mathrm{ppt}$ ) maka dapat berpengaruh buruk terhadap vegetasi mangrove. Menurut Bengen (2000), daerah yang paling dekat dengan substrat agak berpasir, sering ditumbuhi oleh Avicennia sp.

Apabila diperhatikan, $\mathrm{pH}$ perairan tempat tumbuhnya mangrove dekat dengan jalan raya dan dekat dengan rumah warga dihasilkan $\mathrm{pH}$ yang lebih rendah dibandingkan dengan $\mathrm{pH}$ perairan arah paling utara dari lokasi PRPM dekat dengan laut Jawa. $\mathrm{pH}$ yang rendah diketahui bahwa mengalami kondisi asam. Dengan adanya $\mathrm{pH}$ yang rendah, maka akan mengganggu proses pertumbuhan mangrove. $\mathrm{pH}$ yang rendah kemungkinan disebabkan oleh adanya faktor limbah yang dihasilkan oleh sisa pembuangan masyarakat sekitar melalui saluran pembuangan air (selokan) dan kemungkinan juga karena polusi air, udara dan adanya efek hujan asam disekitarnya.

\section{Faktor Penyebab Kerusakan Mangrove}

Apabila diamati, penanaman mangrove di kawasan PRPM belum sesuai dengan formasi yang telah dicantumkan dalam referensi zonasi mangrove. Metode penanaman mangrove yang telah diupayakan oleh pemerintah dan kelompok masyarakat berupa penanaman mangrove pada lokasi yang sudah tersedia jenis mangrove yang sama ditempat tersebut. Misalnya, apabila disebelah barat terdapat mangrove jenis Rhizophora maka akan dilakukan penanaman pohon serupa ditempat itu pula. Wilayah PRPM tergenang air laut secara terus menerus, hal ini disebabkan karena tingginya gelombang pasang dan adanya tembok tanggul yang jebol disisi utara dekat dengan laut Jawa, sehingga air laut mudah sekali masuk dan sulit untuk kembali ke arah laut.daerah yang sering tergenang air laut merupakan daerah yang kurang cocok untuk pertumbuhan mangrove. Harus ada sirkulasi air supaya wilayahnya tidak tergenang. Mangrove dapat tumbuh secara maksimal apabila terdapat sirkulasi air yang cukup, tumbuh sesuai substatnya, tidak ada predasi ataupun hama bagi vegetasi mangrove. tidak ada penebangan liar dan nutrisi substrat yang tercukupi. Onrizal (2005), menyatakan bahwa suksesi terjadi apabila suatu

Tabel 1. Rerata Parameter Lingkungan di PRPM Kota Pekalongan

\begin{tabular}{lllllll}
\hline No & Parameter & Stasiun 1 & Stasiun 2 & Stasiun 3 & Stasiun 4 & Batu mutu \\
\hline 1. & $\mathrm{pH}$ & 7,7 & 7,7 & 7,8 & 7,8 & $6-9$ \\
2. & Do $(\mathrm{mg} / \mathrm{L})$ & 4,3 & 4,5 & 4,1 & 4,2 & $>4$ \\
3. & Indek Bias & 1,019 & 1,019 & 1,019 & 1,019 & $>1$ \\
4. & Suhu $\left({ }^{\circ} \mathrm{C}\right)$ & 31 & 29,8 & 28,0 & 28,0 & $>20$ \\
5. & Salinitas $(\% 00)$ & 25 & 25 & 24,5 & 25 & \pm 35 \\
\hline
\end{tabular}


komunitas tumbuhan mengalami kerusakan akibat berbagai faktor, seperti api, banjir, edafis, dan biotis. Faktor edafis timbul karena pengaruh tanah seperti komposisi tanah, kelembaban tanah, suhu tanah dan keadaan air tanah. Sedangkan biotis adalah faktor yang disebabkan oleh manusia, misalnya penebangan/ pengambilan kayu. Terkait dengan faktorfaktor penyebab kerusakan ekosistem mangrove, Onrizal (2005) menambahkan ada tiga faktor utama penyebab kerusakan mangrove, yaitu (1) pencemaran, (2) konversi hutan mangrove yang kurang memperhatikan faktor lingkungan dan (3) penebangan yang berlebihan.

\section{KESIMPULAN}

Berdasarkan hasil pengamatan di lokasi PRPM Kota Pekalongan, dapat disimpulkan bahwa Mangrove yang mendominasi yaitu Genus Rhizopora. Selain itu ada beberapa Genus lain yang ditemukan antara lain Sonneratia, Avicennia, Bruguiera, Xylocarpus, dan Nypa. Penyebab kerusakan mangrove di lokasi PRPM di karenakan ada dua faktor yaitu faktor alam dan lingkungan/ manusia. Tetapi faktor kerusakan di lokasi PRPM di dominasi oleh faktor alam, di karenakan lahan penanaman mangrove dulu bekas bangunan dan tidak standar formasi untuk penanaman serta sirkulasi air di lokasi tersebut kurang memadai untuk pertumbuhan vegetasi mangrove. Parameter yang mempengaruhi di lokasi PRPM antara lain $\mathrm{pH}, \mathrm{DO}$, temperature, salinitas, dan cahaya. Parameter lingkungan tersebut di lokasi PRPM (Pusat Restorasi dan Pembelajaran Mangrove) sudah memenuhi standar untuk pertumbuhan vegetasi mangrove.

\section{UCAPAN TERIMA KASIH}

Ucapan terima kasih atas bantuan dan kerja-samanya kepada Ria Y. Suraeda yang telah membantu dalam pelaksanaan penelitian hingga penulisan ini.

\section{DAFTAR PUSTAKA}

Amran, M.A. 2000. Pemanfaatan Citra Penginderaan Jauh untuk Inventarisasi Hutan Mangrove. Laboratorium Penginderaan Jauh dan Sistem Informasi Kelautan. Jurusan IImu Kelautan. Universitas Hasanuddin. Makassar.

Anwar, C dan H. Gunawan, 2006. Peranan Ekologis dan Sosial Ekonomis Hutan Mangrovedalam Mendukung Pembangunan Wilayah Pesisir. Pusat Litbang Hutan dan Konservasi Alam Bogor.

Ashton, P.S. 1988. Manual of the NonDipterocarp Trees of Sarawak Volume II.Kuala Lumpur: Dewan Bahasa dan Pustaka Sarawak Branch For Forest Department Sarawak.

Aksornkoae, S. 1993. Ecology and Management of Mangrove. IUCN, Bangkok. Thailand.

Backer, C.A. and R.C. Bakhuizen van den Brink. 1963-1968. Flora of Java. 3 Volumes, N.V.P. Noordhoff, Leiden, The Netherlands.

Bengen, D.G. 2000. Sinopsis Ekosistem dan Sumberdaya Alam Pesisir. Pusat Kajian Sumberdaya Pesisir dan Lautan IPB.

Bengen, D.G. 2001. Pengelolaan Sumberdaya Wilayah Pesisir Secara Terpadu, Berkelanjutan dan Berbasis Masyarakat. Makalah pada Sosialisasi Pengelolaan Sumberdaya Berbasis Masyarakat. Bogor, 21-22 Sept 2001.

Chapman, V.J. 1984. Botanical Surveys in Mangrove Communities. Dalam The mangrove Ecosystem: Research Methods. UNESCO, Monograph on Oceanological Methodology 8, Paris. hal. 53-80.

Ding Hou. 1958. Rhizophoraceae. Flora Malesiana, Ser.l, 5: 429-493.

Departemen Kehutanan. 1982. Potensi dan Penyebaran Hutan Payau di Indonesia. Jakarta: Edisi Khusus No. 40 Direktorat Jendral Kehutanan. Departemen Pertanian. dosen fakultas mipa jurusan biologi universitas pgri palembang http://id.scribd.com/doc/76925991/jur nal Tanggal 15 Agustus 2014.

Fernando, E.S. and J.V. Pancho. 1980. Mangrove trees of the Philippines. Sylvatropica, The Philippines Forest Research Journal5 (1): 33-51. 
Giesen, W. and Sukotjo. 1991. Karang Gading-Langkat Timur Laut Wildlife Reserve(North Sumatra). Laporan Proyek PHPA/AWB Sumatra Wetland No. 10, 48hal.

Giesen, W., Wulffraat, S., Zieren, M., Scholten, L. 2006. Mangrove Guidebook For Southeast Asia. FAO and Wetlands International.

Irwanto, 2006. Keanekaragaman Fauna Pada Habitat mangrove. Yogyakarta .wWw.irwantoshut.com.

Kitamura, S., C. Anwar, A. Chaniago dan S. Baba. 1997. Buku Panduan Mangrove di Indonesia (Bali dan Lombok). JICA-ISME:Denpasar.

Lugo A and SC Snedker. 1974. The Ecology of Mangroves. Annual Review of Ecology and Systematic 5: 39-64.

MacNae, W. 1968. A General Account of the Fauna and Flora of Mangrove
Swampsand Forests in the Indo-WestPacific Region. Adv. mar. Biol., 6: 73270.

Nontji, A. 1987. Laut Nusantara (Marine Nusantara). Djambatan. Jakarta, Indonesia.

Noor, Y.R., M. Khazali, dan I.N.N. Suryadiputra. $1999 . \quad$ Panduan Pengenalan Mangrove di Indonesia. Bogor: Wetlands International Indonesia Programme.

Onrizal. 2005. Evaluasi Kerusakan Kawasan Mangrove dan Alternatif Rehabilitasinya di Jawa Barat dan Banten. Medan: Departemen Kehutanan Fakultas Pertanian USU.

Tomlinson, P.B. 1986. The botany of mangrove.Cambridge University Press. United Kingdom. 